\title{
Brain-Derived Neurotrophic Factor Val66Met Human Polymorphism Impairs the Beneficial Exercise-Induced Neurobiological Changes in Mice
}

\author{
Alessandro leraci",', Alessandro I Madaio', Alessandra Mallei', Francis S Lee ${ }^{2}$ and Maurizio Popoli' \\ 'Laboratory of Neuropsychopharmacology and Functional Neurogenomics, Dipartimento di Scienze Farmacologiche e Biomolecolari and Center of \\ Excellence on Neurodegenerative Diseases, Università di Milano, Milano, Italy; ${ }^{2}$ Department of Psychiatry, Weill Medical College of Cornell \\ University, New York, NY, USA
}

\begin{abstract}
Several studies have shown that exercise improves cognitive functions and emotional behaviors. Positive effects of exercise have been associated with enhanced brain plasticity, adult hippocampal neurogenesis, and increased levels of brain-derived neurotrophic factor (BDNF). However, a substantial variability of individual response to exercise has been described, which may be accounted for by individual genetic variants. Here, we have assessed whether and how the common human BDNF Val66Met polymorphism influences the neurobiological effects modulated by exercise in BDNF Val66Met knock-in male mice. Wild-type (BDNF ${ }^{\text {Val/Val}}$ ) and homozygous BDNF Val66Met (BDNFMet/Met) male mice were housed in cages equipped with or without running wheels for 4 weeks. Changes in behavioral phenotype, hippocampal adult neurogenesis, and gene expression were evaluated in exercised and sedentary control mice. We found that exercise reduced the latency to feed in the novelty suppressed feeding and the immobility time in the forced swimming test in BDNF ${ }^{\mathrm{Val} / \mathrm{Val}}$ but not in BDNF ${ }^{\text {Met/Met }}$ mice. Hippocampal neurogenesis was reduced in BDNF Met/Met mice compared with BDNF ${ }^{\mathrm{Val} / \mathrm{Nal}}$ mice. BDNF ${ }^{\text {Met/Met }}$ mice had lower basal BDNF protein levels in the hippocampus, which was not recovered following exercise. Moreover, exercise-induced expression of total BDNF, BDNF splice variants I, 2, 4, 6 and fibronectin type III domain-containing protein 5 (FNDC5) mRNA levels were absent or reduced in the dentate gyrus of BDNF ${ }^{\text {Met/Met }}$ mice. Exercise failed to enhance PGC- $\alpha$ and FNDC5 mRNA levels in the BDNF ${ }^{\text {Met/Met }}$ muscle. Overall these results indicate that, in adult male mice, the BDNF Val66Met polymorphism impairs the beneficial behavioral and neuroplasticity effects induced by physical exercise.

Neuropsychopharmacology (2016) 4I, 3070-3079; doi:I0.1038/npp.2016.120; published online I0 August 20I6
\end{abstract}

\section{INTRODUCTION}

Several studies have shown that regular physical exercise is beneficial for physical and mental health at all ages, including the elderly. Exercise improves mental health by reducing anxiety, depression, negative mood and by improving selfesteem and cognitive functions (Deslandes et al, 2009; Duman et al, 2008; Schuch et al, 2016; Voss et al, 2013). Moreover, some lines of evidence strongly suggest that individuals who are physically active during adulthood tend to have better cognitive performances later in life (Mattson, 2015). Exercise-induced improvement in brain function has been associated with increased adult hippocampal neurogenesis, synaptogenesis, and enhanced activity-dependent synaptic plasticity (Christie et al, 2008; Farmer et al, 2004;

*Correspondence: Dr A leraci, Laboratory of Neuropsychopharmacology and Functional Neurogenomics, Dipartimento di Scienze Farmacologiche e Biomolecolari, Università di Milano, Via Balzaretti 9, Milano 20133, Italy. Tel: +39 02503|835I; Fax: +39 02503।8278. E-mail: alessandro.ieraci@unimi.it

Received 3 May 2016; revised I5 June 2016; accepted 27 June 2016; accepted article preview online 8 July 2016
Stranahan et al, 2007; van Praag et al, 1999; Vivar et al, 2013). One of the major mechanisms proposed whereby exercise affects brain plasticity and function is the increase of brain-derived neurotrophic factor (BDNF), a neurotrophin implicated in anxiety, depression, learning, and memory disabilities (Hopkins et al, 2011; Ieraci et al, 2015; Intlekofer et al, 2013; Phillips et al, 2014; Vaynman et al, 2004; Voss et al, 2013). However, the mechanism underlying the exercise-induced BDNF expression in the hippocampus is still poorly understood.

Recently, it has been reported that exercise enhances the expression of fibronectin type III domain-containing protein 5 (FNDC5) in the muscle, in a peroxisome proliferatoractivated receptor- $\gamma$ coactivator- $1 \alpha$ (PGC- $1 \alpha$ )-dependent manner (Wrann et al, 2013). FNDC5 is a transmembrane protein released in the blood stream after proteolytic cleavage (Bostrom et al, 2012). Importantly, overexpression of FNDC5 into liver via adenovirus infection significantly enhances BDNF expression in the hippocampus (Wrann et al, 2013). Interestingly, BDNF in turn is able to reduce the expression of FNDC5 suggesting a homeostatic feedback 
loop (Wrann et al, 2013). However, whether BDNF genetic variants may alter this pathway is still unknown.

Despite the well-documented positive effects of exercise in humans, substantial variability in the individual response has been reported. This variability may be accounted for by genetic factors that interfere with the benefit of exercise on cognitive functions and mood.

A number of common single-nucleotide polymorphisms (SNPs) have been identified in the human BDNF gene. The rs6265 SNP leads to a Valine to Methionine substitution at position 66 (Val66Met) in the pro-domain of BDNF, which impairs the activity-dependent release of BDNF. Val66Met SNP is associated with increased susceptibility to cognitive deficits and neuropsychiatric disorders (Egan et al, 2003; Hariri et al, 2003; Lim et al, 2014; Notaras et al, 2015; Verhagen et al, 2010). Despite the strong evidence that exercise increases BDNF expression, only a few human studies have been conducted to address the potential role of Val66Met SNP in moderating exercise response, showing inconclusive results, probably due to confounding factors (Brown et al, 2014; Gujral et al, 2014; Hopkins et al, 2012; Lemos et al, 2016; Mata et al, 2010; Nascimento et al, 2015). Animal models may offer a useful tool to better address such question in a well-controlled environment and genetic setting.

A knock-in mouse carrying the human BDNF Val66Met SNP has been generated (Chen et al, 2006). BDNF ${ }^{\mathrm{Met} / \mathrm{Met}}$ homozygous mice recapitulate the phenotypic hallmarks of humans carrying the BDNF Met allele. Indeed, BDNF${ }^{\mathrm{Met} / \mathrm{Met}}$ mice display reduced hippocampal volume, reduced dendritic arborization in the dentate gyrus (DG), reduced BDNF levels, and NMDA receptor-dependent synaptic plasticity in the hippocampus (Chen et al, 2006; Ninan et al, 2010). Furthermore, we have recently found decreased expression and dendritic trafficking for selected BDNF transcripts in $\mathrm{BDNF}^{\text {Met/Met }}$ hippocampus (Mallei et al, 2015). Interestingly, $\mathrm{BDNF}^{\mathrm{Met} / \mathrm{Met}}$ mice are unresponsive to treatment with some antidepressant drugs, in particular it has been reported that chronic fluoxetine treatment and acute ketamine administration do not promote anxiolytic and antidepressant-like effects, respectively, in $\mathrm{BDNF}^{\mathrm{Met} / \mathrm{Met}}$ mice (Chen et al, 2006; Liu et al, 2012). Thus, this mouse may provide an ideal model to explore whether and by what mechanism(s) the Val66Met SNP moderates the effects of environmental and pharmacological treatments.

In this study, we assessed the effect of exercise on anxiousand depressive-like behaviors in $\mathrm{BDNF}^{\mathrm{Val} / \mathrm{Val}}$ wild-type and $\mathrm{BDNF}^{\text {Met/Met }}$ mutant adult male mice. We explored the possible mechanisms underlying the exercise-induced behavioral changes by measuring the levels of neurogenesis and BDNF expression in the hippocampus of BDNF ${ }^{\mathrm{Val} / \mathrm{Val}}$ and $\mathrm{BDNF}^{\mathrm{Met} / \mathrm{Met}}$ mice exposed to exercise. Finally, we investigated whether exercise-induced PGC- $1 \alpha$ and FNDC5 expressions were altered in $\mathrm{BDNF}^{\mathrm{Met} / \mathrm{Met}}$ mice.

\section{MATERIALS AND METHODS}

\section{Animals}

Adult male 3- to 4-month-old $\mathrm{BDNF}^{\mathrm{Met} / \mathrm{Met}}$ and $\mathrm{BDNF}^{\mathrm{Val} / \mathrm{Val}}$ mice were used for all studies (Chen et al, 2006). Mice were maintained in a standard $12 \mathrm{~h}$ light/dark cycle, temperature controlled room $\left(21 \pm 1^{\circ} \mathrm{C}\right)$, with free access to food and water.

All experimental procedures involving animals were performed in accordance with the European Community Council Directive 86/609/EEC, and were approved by Italian legislation on animal experimentation (Decreto Legislativo $116 / 1992)$.

\section{Behavioral Tests}

Behavioral tests were conducted between 0900 and $1600 \mathrm{~h}$. See Supplementary Materials and Methods for more details.

\section{BrdU Treatment and Immunohistochemistry}

Detailed information can be found in Supplementary Materials and Methods.

\section{BDNF ELISA}

BDNF levels were measured by an enzyme-linked immunosorbent assay (ELISA) according to the manufacturer's instructions (BDNF Emax Immunoassay System, Promega).

\section{Western Blot}

Detailed western blot procedures can be found in Supplementary Materials and Methods.

\section{RNA Isolation and Quantitative Real-Time PCR}

Detailed information is reported in Supplementary Materials and Methods.

\section{Statistical Analysis}

Statistical analyses were performed using GraphPad Prism 6 (GraphPad Software, La Jolla, CA). Data are presented as mean \pm standard error of the mean (SEM). Statistical analyses were made using unpaired $t$-test or two-way analysis of variance (ANOVA), and Fischer's LSD post hoc test was used for multiple comparison analysis.

\section{RESULTS}

\section{Physical Exercise-Induced Reduction of Body Weight Gain}

Adult male $\mathrm{BDNF}^{\mathrm{Val} / \mathrm{Val}}$ and $\mathrm{BDNF}^{\mathrm{Met} / \mathrm{Met}}$ mice underwent 4 weeks of free voluntary exercise. $\mathrm{BDNF}^{\mathrm{Val} / \mathrm{Val}}$ and $\mathrm{BDNF}^{\text {Met/Met }}$ displayed similar daily running distance $(P=0.3001$; Figure 1a). However, we found a main body weight gain effect for exercise and genotype (exercise: $\mathrm{F}_{(1,186)}=9.204 ; P=0.0028$; genotype: $\mathrm{F}_{(1,186)}=3.962 ; P=0.048$; interaction: $\left.\mathrm{F}_{(1,186)}=0.647 ; P=0.422\right)$. Exercise significantly reduced the body weight gain in both genotypes although this effect was apparently less evident in $\mathrm{BDNF}^{\text {Met/Met }}$ mutant mice (Figure 1b). The exercise-induced reduction of body weight was not due to differences in starting weight (Supplementary Figure S1). Interestingly, the daily food consumption was affected by both the exercise and genotype factors (exercise: $\mathrm{F}_{(1,56)}=11.13 ; P=0.0015$; genotype: 
a Daily Running Distance

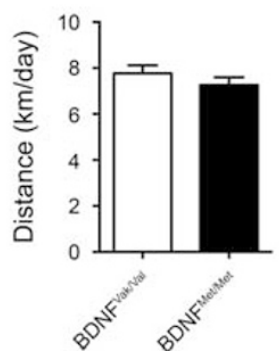

d

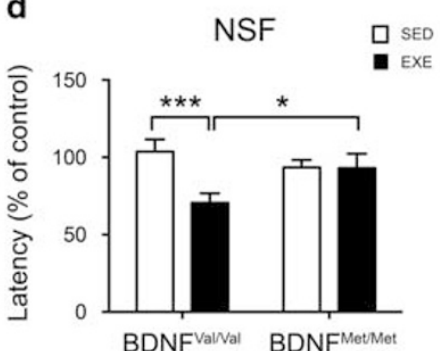

b

Body Weight Change

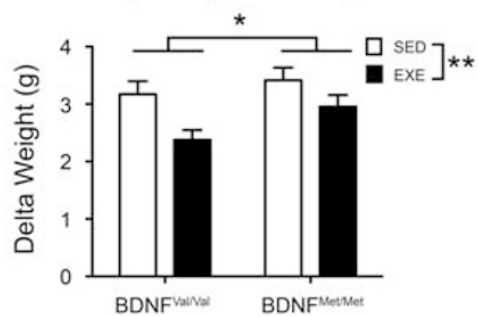

e

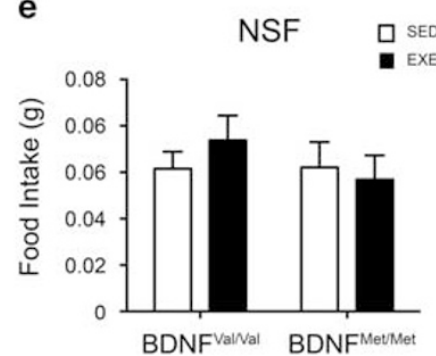

C

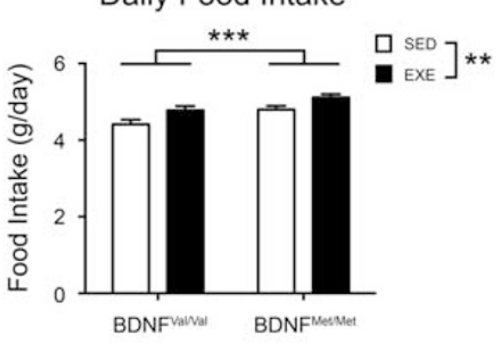

Figure I BDNF Val66Met polymorphism impairs physical exercise-induced beneficial effect of physical exercise on anxious- and depressive-like phenotype in mice. (a) Total distance run daily by mice. Daily running distance was calculated by dividing for 2 the distance measured by a single electronic counter (two electronic counter per cage; four mice per cage). Data are expressed as means \pm SEM ( $n=35-39$ number of electronic counters analyzed per group). Unpaired t-test. (b) Total body weight gain over 4 weeks of physical exercise treatment ( $n=45-52$ mice per group). (c) Daily food consumption. Amount of daily food intake per mice was calculated by dividing for 4 the total amount of food consumed per cage (four mice per cage) ( $n=14-16$ number of cage analyzed per group). (d, e) Novelty suppressed feeding (NSF) test. (d) Exercise reduces the latency to feed in NSF test only in BDNF ${ }^{\text {Val } / \mathrm{Val}}$ mice. (e) There is no difference in the amount of food consumed in the home cages among all the groups. (f) Forced swimming test (FST). Exercise decreases the immobility time only in BDNF ${ }^{\mathrm{Val} / \mathrm{Val}}$ mice. Data are expressed as means \pm SEM ( $n=18-24$ mice per group). Two-way ANOVA followed by Fischer's LSD post hoc analysis. $* P<0.05$; $* * P<0.01$; ${ }^{* * *} P<0.00$ I. EXE, exercise; SED, sedentary.

$\mathrm{F}_{(1,56)}=12.52 ; P=0.0008$; interaction: $\left.\mathrm{F}_{(1,56)}=0.068 ; P=0.7949\right)$. Running mice consumed more food than the corresponding sedentary group and $\mathrm{BDNF}^{\mathrm{Met} / \mathrm{Met}}$ ate more food than $\mathrm{BDNF}^{\mathrm{Val} / \mathrm{Val}}$ mice (Figure 1c).

\section{Physical Exercise-Induced Beneficial Behavioral Changes Are Impaired in the $\mathrm{BDNF}^{\text {Met/Met }}$ Mutant Mice}

First, we assessed whether the BDNF Val66Met SNP moderates the exercise-induced decrease of anxiety- and depression-like behaviors in mice, using the novelty suppressed feeding (NSF) and the forced swimming test (FST), respectively. The results from the NSF test showed a significant main effect for exercise and for the interaction between exercise and genotype (exercise: $\mathrm{F}_{(1,80)}=5.207$; $P=0.025$; genotype: $\mathrm{F}_{(1,80)}=0.704 ; \quad P=0.404$; interaction: $\mathrm{F}_{(1,80)}=4.923 ; P=0.0293$ ) (Figure 1d). Fisher post hoc analysis revealed that exercise reduces the latency to feed only in the $\mathrm{BDNF}^{\mathrm{Val} / \mathrm{Val}}$ mice (Figure 1d). Moreover $\mathrm{BDNF}^{\mathrm{Val} / \mathrm{Val}}$ runner mice exhibited a significant reduction of latency time compared with running $\mathrm{BDNF}^{\mathrm{Met} / \mathrm{Met}}$ mice (Figure 1d). As a control, there were no significant changes in food consumption measured in the home cage for a period of 5 min immediately after the NSF test between genotypes (sedentary and running) (exercise: $\mathrm{F}_{(1,80)}=0.124 ; P=0.725$; genotype: $\mathrm{F}_{(1,80)}=0.678 ; P=0.413$; interaction: $\mathrm{F}_{(1,80)}=0.788$; $P=0.377$ ) (Figure 1e).

In the FST, there was a main effect for the interaction exercise $\times$ genotype $\quad$ (exercise: $\quad \mathrm{F}_{(1,80)}=2.701 ; \quad P=0.104$; genotype: $\quad \mathrm{F}_{(1,80)}=1.074 ; \quad P=0.303 ; \quad$ interaction: $\left.\mathrm{F}_{(1,80)}=6.591 ; P=0.0121\right)$. The immobility time was reduced in the $\mathrm{BDNF}^{\mathrm{Val} / \mathrm{Val}}$ exercise mice group compared with the sedentary $\mathrm{BDNF}^{\mathrm{Val} / \mathrm{Val}}(P=0.0019)$ and the $\mathrm{BDNF}^{\mathrm{Met} / \mathrm{Met}}$ exercise $(P=0.0127)$ mice groups (Figure 1f). Altogether, the data from NSF and FST tests suggest that the BDNF Val66Met polymorphism impairs the beneficial behavioral effects induced by exercise.

\section{Neurogenesis in the DG Is Diminished in the BDNF $^{\text {het/Met }}$ Mutant Mice}

Increase of neurogenesis in hippocampal DG is recognized as a major effect of exercise in mice. Therefore, we assessed whether the exercise-induced behavioral changes observed in the two genotypes were related to variations of neurogenesis in the DG. To measure the survival of newborn neurons, mice were injected with BrdU once-daily for 7 days and killed 3 weeks after the last injection (Figure 2a). We found that exercise increased the number of surviving newborn neurons in the DG of both $\mathrm{BDNF}^{\mathrm{Val} / \mathrm{Val}}$ and $\mathrm{BDNF}^{\mathrm{Met} / \mathrm{Met}}$ mice (exercise: $\mathrm{F}_{(1,32)}=84.54 ; P<0.0001$ ). We also found a main effect for the genotype (genotype: $\mathrm{F}_{(1,32)}=5.23$; $P=0.029$; interaction: $\left.\mathrm{F}_{(1,32)}=1.655 ; P=0.208\right)$, indicating that the overall neurogenesis is lower in the $\mathrm{BDNF}^{\mathrm{Met} / \mathrm{Met}}$ mice and this difference was bigger in exercised mice $(P=0.0167)$ (Figure $2 \mathrm{~b}-\mathrm{d})$. In order to measure an endogenous marker of neurogenesis, we quantified the total number of neuroblasts expressing doublecortin (DCX) in the 
a

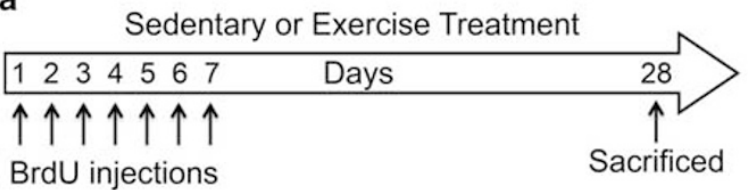

b

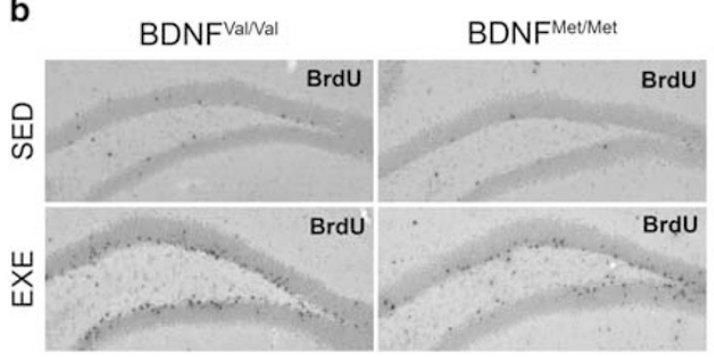

d

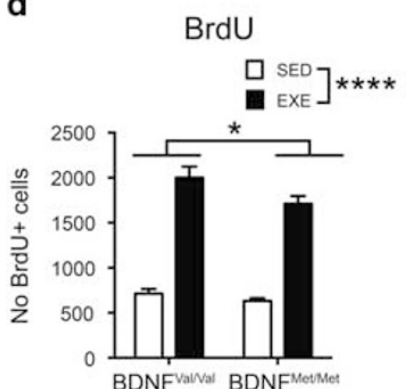

e
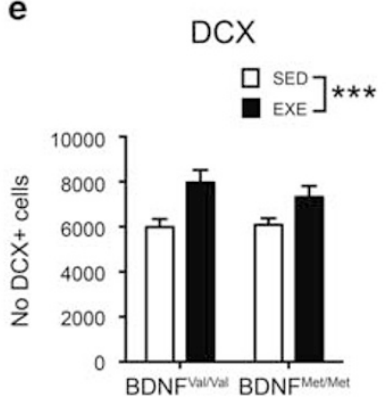

c

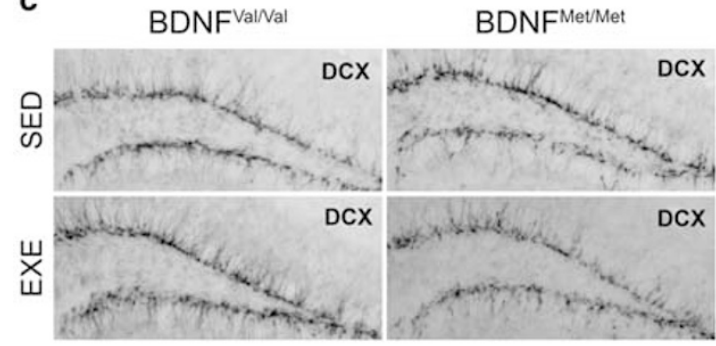

f

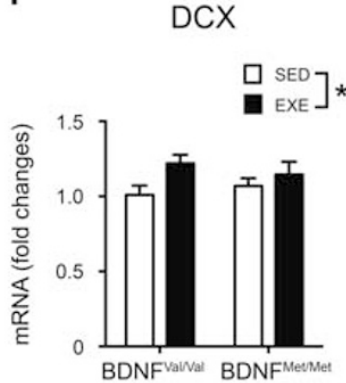

g

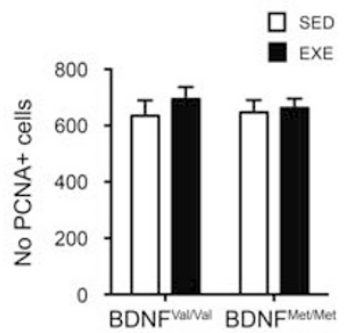

Figure 2 BDNF Val66Met polymorphism reduces hippocampal neurogenesis in mice. (a) Schematic representation of the experimental procedure. Mice were injected with BrdU for 7 days and killed 21 days after the last injection. (b, c) Images of BrdU and DCX immunostaining in the DG. (d) Total amount of BrdU-positive cells in the DG ( $n=9$ mice per group). (e, f) Exercise significantly increases the total amount of DCX-positive cells ( $n=9$ mice per group) and DCX mRNA levels ( $n=6-7$ mice per group) in the DG. (g) There is no significant difference in the number of PCNA-positive cells among all the groups ( $n=6$ mice per group). Data are expressed as means \pm SEM. Two-way ANOVA. $* P<0.05$; $* * * *<0.00$ I; $* * * * P<0.000$ I. EXE, exercise; SED, sedentary.

DG. A two-way ANOVA revealed only a significant overall effect for exercise (exercise: $\mathrm{F}_{(1,32)}=13.48 ; \quad P=0.0009$; genotype: $\quad \mathrm{F}_{(1,32)}=0.377 ; \quad P=0.543$; interaction: $\mathrm{F}_{(1,32)}=0.709 ; P=0.406$ ) (Figure $3 \mathrm{c}-\mathrm{e}$ ). A similar result was obtained by measuring the DCX mRNA levels in the DG (exercise: $\mathrm{F}_{(1,22)}=4.452 ; P=0.0465$; genotype: $\mathrm{F}_{(1,22)}=0.009$; $P=0.924$; interaction: $\mathrm{F}_{(1,22)}=1.002 ; P=0.328$ ) (Figure 2f). To assess whether the number of proliferating cells was also differentially affected we performed an immunohistochemistry staining for the proliferating cell nuclear antigen (PCNA), an endogenous marker of ongoing cell proliferation. We did not find significant changes in the number of PCNA-positive cells measured throughout the DG (exercise: $\mathrm{F}_{(1,20)}=0.693 ; P=0.415$; genotype: $\mathrm{F}_{(1,20)}=0.052 ; P=0.822$; interaction: $\mathrm{F}_{(1,20)}=0.24 ; P=0.629$ ) (Figure $2 \mathrm{~g}$ ). Overall, the combined data suggest that exercise mainly favors survival of new neuron after 4 weeks, but not their proliferation, and this effect is bigger in $\mathrm{BDNF}^{\mathrm{Val} / \mathrm{Val}}$ mice.

\section{Physical Exercise-Induced BDNF Expression in the Hippocampus Is Impaired in the $\mathrm{BDNF}^{\text {Met/Met }}$ Mutant Mice}

It has been proposed that exercise-induced behavioral changes are mediated by elevation of BDNF and its receptor TrkB in the hippocampus (Liu et al, 2008; Vaynman et al, 2004). Therefore, we examined whether the BDNF Val66Met polymorphism affects the exercise-induced augmentation of hippocampal BDNF and $\operatorname{TrkB}$ levels in mice. Analysis of total BDNF mRNA levels revealed that the overall BDNF levels in whole hippocampus were increased by exercise (exercise: $\mathrm{F}_{(1,37)}=6.633 ; P=0.0141$ ). However, BDNF mRNA levels were lower in $\mathrm{BDNF}^{\mathrm{Met} / \mathrm{Met}}$, both in sedentary and in exercised mice (genotype: $\mathrm{F}_{(1,37)}=7.988 ; P=0.0076$; interaction: $\mathrm{F}_{(1,37)}=1.496 ; P=0.2291$ ) (Figure 3a). Next, we evaluated the effect of exercise on the hippocampal BDNF protein levels in the $\mathrm{BDNF}^{\mathrm{Val} / \mathrm{Val}}$ and $\mathrm{BDNF}^{\mathrm{Met} / \mathrm{Met}}$ mice, using the ELISA method. As previously reported (Bath et al, 2012), we found that $\mathrm{BDNF}$ protein levels in the $\mathrm{BDNF}^{\mathrm{Met} / \mathrm{Met}}$ mice were significantly lower compared with $\mathrm{BDNF}^{\mathrm{Val} / \mathrm{Val}}$ mice (genotype: $\left.\mathrm{F}_{(1,44)}=52.26 ; P<0.0001\right)$. Interestingly, although exercise significantly increased the overall BDNF protein levels in the whole hippocampus of both genotypes (exercise: $\mathrm{F}_{(1,44)}=8.217 ; \quad P=0.0063 ; \quad$ interaction: $\quad \mathrm{F}_{(1,44)}=1.775$; $P=0.189$ ), this increase was limited in the $\mathrm{BDNF}^{\mathrm{Met} / \mathrm{Met}}$ mice, in which BDNF level remained significantly lower than in $\mathrm{BDNF}^{\mathrm{Val} / \mathrm{Val}}$ sedentary mice $\left(\mathrm{BDNF}^{\mathrm{Val} / \mathrm{Val}}\right.$ sedentary $114.6 \pm 6.398$ vs $\mathrm{BDNF}^{\mathrm{Met} / \mathrm{Met}}$ exercise $73.67 \pm 10.04$; $P<0.01$ ) (Figure $3 b$ ). Finally, we measured the hippocampal TrkB protein levels by western blot. We found that TrkB protein levels were overall higher in $\mathrm{BDNF}^{\mathrm{Met} / \mathrm{Met}}$ mice and modulated by exercise (exercise: $\mathrm{F}_{(1,44)}=4.623 ; P=0.0371$; genotype: $\mathrm{F}_{(1,44)}=5.463 ; P=0.0024$; interaction: $\mathrm{F}_{(1,44)}=0.615$; $P=0.437$ ) (Figure $3 c$ and $d$ ). 

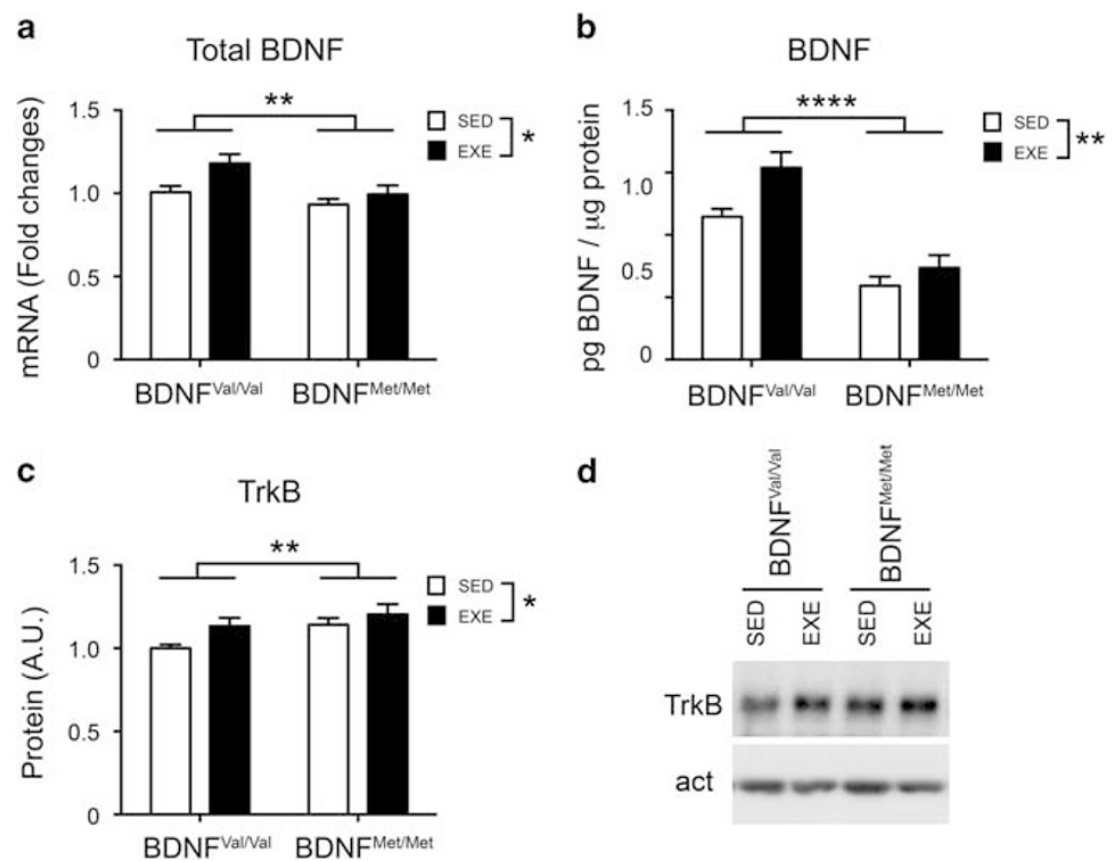

d

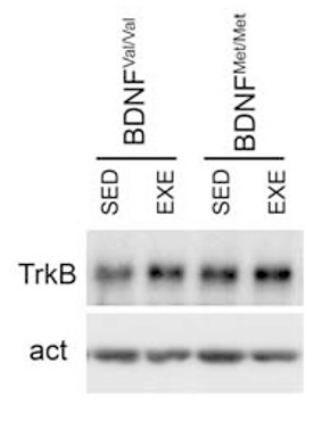

Figure 3 BDNF Val66Met polymorphism impairs BDNF and TrkB expression in mice hippocampus. (a, b) Total hippocampal BDNF mRNA ( $n=\mid 0-1$ I mice per group) and protein levels ( $n=12$ mice per group) are increased after 28 days of physical exercise and reduced in BDNF Met/Met mice. (c) TrkB protein levels in the hippocampus (HPC) are upregulated by physical exercise. (d) Representative western blot pictures from TrkB and $\beta$-actin ( $n=12$ mice per group). Data are expressed as means \pm SEM. Two-way ANOVA. * $P<0.05$; ** $P<0.01$; ***** $P<0.000$ I. EXE, exercise; SED, sedentary.

The hippocampus is a non-homogenous region expressing different cell types and markers in the DG, CA1, CA2, and CA3 regions. Moreover, the BDNF gene has a complex structure and its transcription is regulated by several noncoding $5^{\prime}$ exons alternatively spliced to one $3^{\prime}$ common exon that encodes for the pro-BDNF protein. The complex BDNF gene structure allows the distinct BDNF transcripts to be differentially modulated during development and adulthood, in different brain regions, cell types, and subcellular compartments. (Aid et al, 2007; Lyons and West, 2011). In particular, it has been demonstrated that BDNF transcripts are specifically segregated within the soma (BDNFs 1 and 4) or the dendrites (BDNFs 2 and 6), therefore working as a spatial code (Baj et al, 2012, 2013; Mallei et al, 2015).

Therefore, we sought to explore whether (1) the exerciseinduced expression of BDNF was specific for a particular hippocampal sub-region and (2) what are the BDNF splice variants responsible for the variation of total BDNF mRNA expression after exercise. To this aim, we dissected the DG from the remaining part of the hippocampus (collectively indicated as CA). The accuracy of our dissection was evaluated by measuring the mRNA levels of tryptophan 2,3-dioxygenase (TDO2) and TYRO3 protein tyrosine kinase 3 (Tyro3), two markers specifically expressed in the DG and in the CA regions, respectively (Hagihara et al, 2009), which revealed a clear separation of the two areas (Supplementary Figure S2). First, we assessed the total BDNF mRNA levels, finding that BDNF mRNA expression was higher in the DG compared with the remaining $\mathrm{CA}$ regions and that BDNF expression was modulated by exercise only in the DG area (area: $\mathrm{F}_{(1,44)}=106.8 ; \quad P<0.0001 ;$ groups: $\mathrm{F}_{(3,44)}=14.38$; $P<0.0001$; interaction: $\left.\mathrm{F}_{(1,44)}=5.119 ; P=0.004\right)$. Specifically, exercise increased BDNF mRNA levels only in the DG of $\mathrm{BDNF}^{\mathrm{Val} / \mathrm{Val}}$ mice $(P<0.0001)$ (Figure 4a). Next, we evaluated the levels of BDNF-1; BDNF-2, BDNF-4, and BDNF-6, which are the major transcript splice variants expressed in the hippocampus. We found that BDNF-1 and BDNF-2 were roughly equally expressed in the DG and CA regions and that their expression was increased by exercise in the two regions in both $\mathrm{BDNF}^{\mathrm{Val} / \mathrm{Val}}$ and $\mathrm{BDNF}^{\mathrm{Met} / \mathrm{Met}}$ mice, although at lower extent in $\mathrm{BDNF}^{\mathrm{Met} / \mathrm{Met}}$ mice (BDNF-1: area: $\quad \mathrm{F}_{(1,44)}=0.113 ; \quad P=0.738 ; \quad$ groups: $\mathrm{F}_{(3,44)}=14.59$; $P<0.0001$; interaction: $\mathrm{F}_{(1,44)}=4.604 ; P=0.007 ;$ BDNF-2: area: $\mathrm{F}_{(1,44}<0.0001 ; \quad P=0.9948 ;$ groups: $\mathrm{F}_{(3,44)}=24.10$; $P<0.0001$; interaction: $\mathrm{F}_{(1,44)}=4.164 ; P=0.0111$ ) (Figure 5b and c). For BDNF-4, we found only a main effect for the groups (area: $\mathrm{F}_{(1,44}=2.982 ; P=0.0912$; groups: $\mathrm{F}_{(3,44)}=4.569$; $P=0.0072$; interaction: $\left.\mathrm{F}_{(1,44)}=0.8618 ; P=0.468\right)$ and a further comparison among the groups revealed that BDNF-4 mRNA levels were significantly different in the $\mathrm{BDNF}^{\mathrm{Val} / \mathrm{Val}}$ exercised mice compared with $\mathrm{BDNF}^{\mathrm{Val} / \mathrm{Val}}$ sedentary and $\mathrm{BDNF}^{\mathrm{Met} / \mathrm{Met}}$ exercised mice in the DG (Figure 4d). BDNF-6 mRNA levels were differentially expressed in the different areas and groups (area: $\mathrm{F}_{(1,44}=240$; $P<0.0001$; groups: $\mathrm{F}_{(3,44)}=12.58 ; p P<0.0001$; interaction: $\left.\mathrm{F}_{(1,44)}=4.466 ; P=0.008\right)$. In particular, we found that BDNF-6 was markedly higher in the DG compared with the CA regions $(P<0.0001)$; the BDNF-6 levels were lower in the DG of $\mathrm{BDNF}^{\mathrm{Met} / \mathrm{Met}}$ than in $\mathrm{BDNF}^{\mathrm{Val} / \mathrm{Val}}(P=0.0146)$; and exercise significantly enhanced BDNF-6 expression exclusively in the DG of $\mathrm{BDNF}^{\mathrm{Val} / \mathrm{Val}}$ mice $(P=0.0004)$ (Figure 4e). Finally, we measured the mRNA levels of TrkB, and found a higher TrkB expression in the CA regions with respect to DG (area: $\mathrm{F}_{(1,44}=43.36 ; P<0.0001$; groups: $\mathrm{F}_{(3,44)}=2.699 ; P=0.0572$; interaction: $\mathrm{F}_{(1,44)}=0.411$; $P=0.746$ ) (Figure $4 \mathrm{f}$ ). 


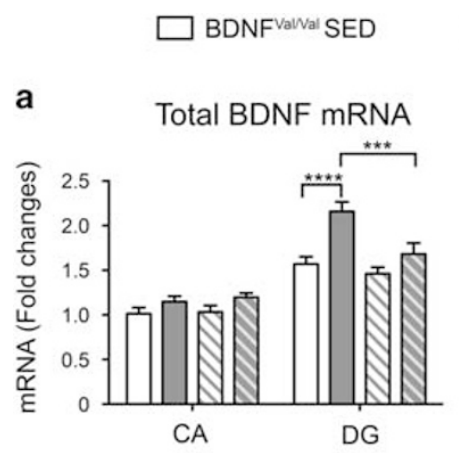

b
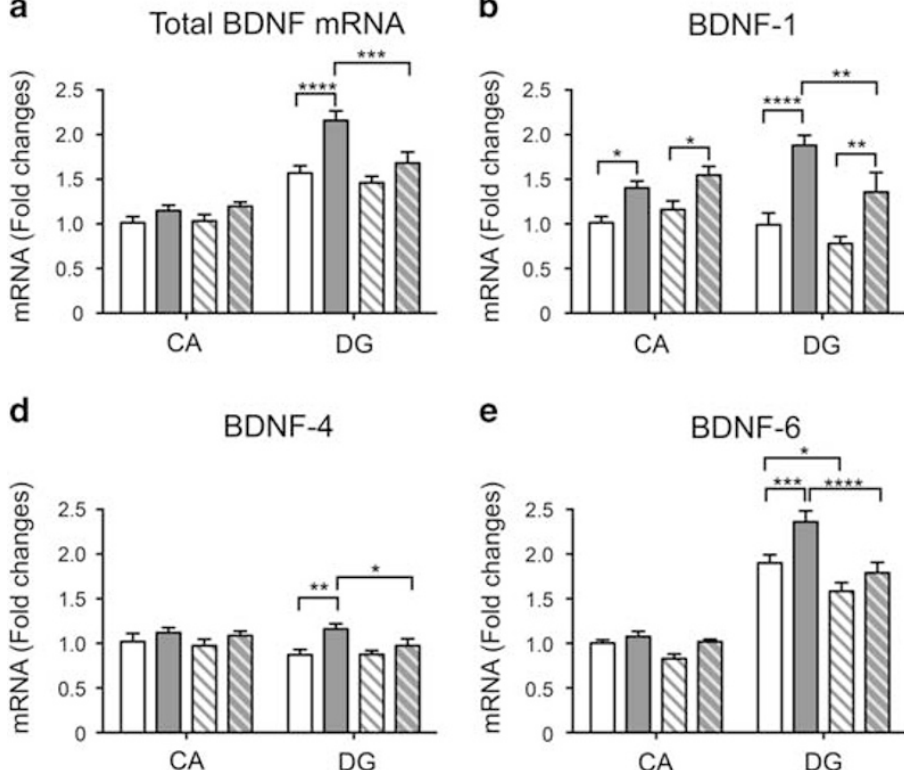

e

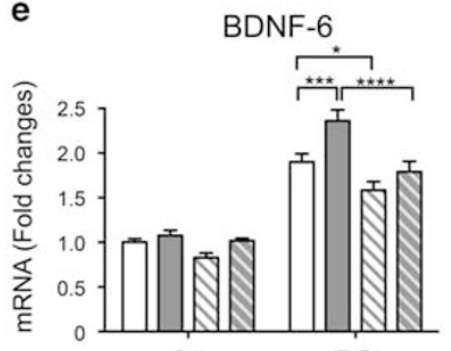

CA c

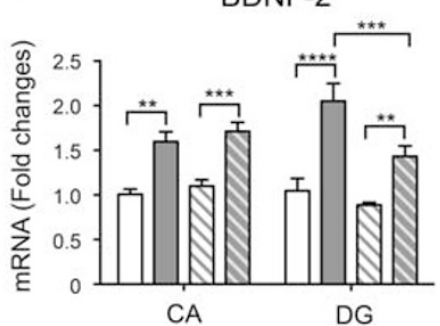

f

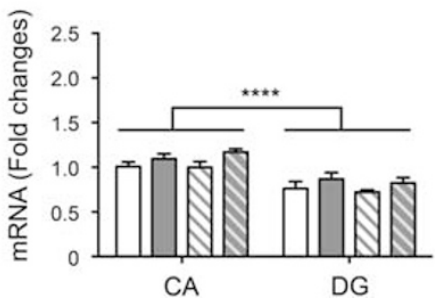

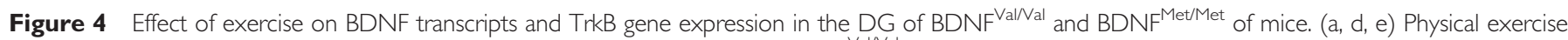

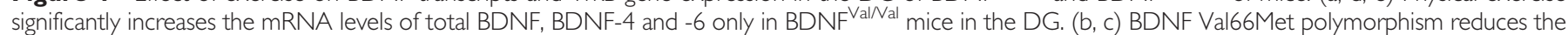

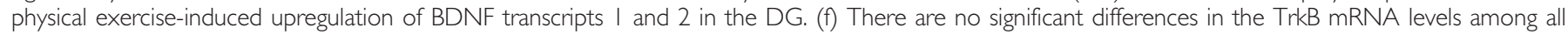

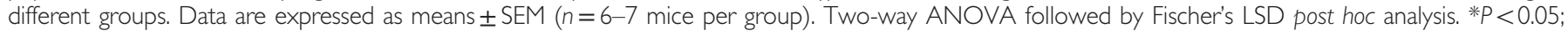
*** $P<0.01$; **** $P<0.001$; ***** $P<0.0001$. CA, cornus ammonis; DG, dentate gyrus; EXE, exercise; SED, sedentary.

\section{Physical Exercise-Induced PGC-1 $\alpha$ and FNDC5 Expressions Are Impaired in the $\mathrm{BDNF}^{\text {Met/Met }}$ Mutant Mice}

Recently, it has been reported that exercise stimulates the production and release of factors in skeletal muscle that are able to affect the hippocampal BDNF expression (Wrann et al, 2013). In particular, exercise increases the expression of the co-activator transcriptional factor PGC- $1 \alpha$, which in turn controls the expression of FNDC5 in the skeletal muscle. FNDC5 is then cleaved, and the product released in the blood stream is able to stimulate the hippocampal BDNF expression with an as yet unidentified mechanism (Bostrom et al, 2012; Wrann et al, 2013). Therefore, we decided to explore whether the BDNF Val66Met polymorphism affects also the basal and exercise-induced mRNA expression of PGC- $1 \alpha$ and FNDC5 in the gastrocnemius muscle. In agreement with previous reports, the mRNA levels of PGC- $1 \alpha$ and FNDC5 were enhanced in $\mathrm{BDNF}^{\mathrm{Val} / \mathrm{Val}}$ wild-type runner mice compared with $\mathrm{BDNF}^{\mathrm{Val} / \mathrm{Val}}$ sedentary mice (PGC- $1 \alpha$ : exercise: $\mathrm{F}_{(1,41)}=0.755 ; \quad P=0.39$; genotype: $\mathrm{F}_{(1,41)}=0.139$; $P=0.71$; interaction: $\mathrm{F}_{(1,41)}=8.285 ; P=0.0063$ : post hoc $P=0.0129$; FNDC5: exercise: $\mathrm{F}_{(1,41)}=1.55 ; P=0.22$; genotype: $\mathrm{F}_{(1,41)}=0.1178 ; P=0.676$; interaction: $\mathrm{F}_{(1,41)}=6.622$; $P=0.014$ : post hoc $P=0.0114$ ) (Figure 5a and $\mathrm{b}$ ). Surprisingly, the basal level of PGC-1 $\alpha$ and FNDC5 was higher in the muscle of $\mathrm{BDNF}^{\mathrm{Met} / \mathrm{Met}}$ mice than in $\mathrm{BDNF}^{\mathrm{Val} / \mathrm{Val}}$ mice (PGC-1 $\alpha$ : $P=0.0216$; FNDC5: $P=0.033$ ), and was not further modulated by exercise (PGC-1 $\alpha$ : $P=0.16$; FNDC5: $P=0.335$ ) (Figure $5 \mathrm{a}$ and $\mathrm{b}$ ).

Next, we measured the mRNA levels of these genes also in the different regions of the hippocampus. We found that
mRNA levels of FNDC5 were differentially expressed in the two regions and in the groups (FNDC5: area: $\mathrm{F}_{(1,44)}=34.71$; $P<0.0001$; groups: $\mathrm{F}_{(3,44)}=2.909 ; \quad P=0.045$; interaction: $\left.\mathrm{F}_{(3,44)}=0.481 ; P=0.6972\right)$. A further comparison among the groups revealed a significant difference only between the sedentary and exercise $\mathrm{BDNF}^{\mathrm{Val} / \mathrm{Val}}$ mice in the $\mathrm{DG}$ $(P=0.0262)$ (Figure 5d). On the contrary, the levels of PGC- $1 \alpha$ were not significantly modified in any of the different conditions (PGC- $1 \alpha$ : area: $\mathrm{F}_{(1,44)}=39.17 ; P<0.0001$; groups: $\mathrm{F}_{(3,44)}=0.788 ; P=0.507$; interaction: $\mathrm{F}_{(3,44)}=0.127$; $P=0.944$ ) (Figure 5c).

Altogether, these results indicate that FNDC5 mRNA expression levels were differentially altered in both the gastrocnemius muscle and hippocampus in basal condition and following exercise exposure in the $\mathrm{BDNF}^{\mathrm{Met} / \mathrm{Met}}$ respect to the $\mathrm{BDNF}^{\mathrm{Val} / \mathrm{Val}}$ mice, while PGC-1 $\alpha$ levels were modulated only in the muscle.

\section{DISCUSSION}

\section{Physical-Exercise Induced Anxiolytic- and Antidepressant-Like Response Is Impaired in BDNF $^{\text {Met/Met }}$ Mutant Mice}

In the present study, we reported for the first time that exercise-induced anxiolytic- and antidepressant-like response is impaired in adult male $\mathrm{BDNF}^{\text {Met/Met }}$ mutant mice. These deficiencies were associated with reduced neurogenesis and BDNF levels in the $\mathrm{BDNF}^{\text {Met/Met }}$ hippocampus. Remarkably, we have found that exercise-induced FNDC5 expression in the muscle and DG is also impaired in $\mathrm{BDNF}^{\mathrm{Met} / \mathrm{Met}}$ mutant mice. These differences in behavior and 


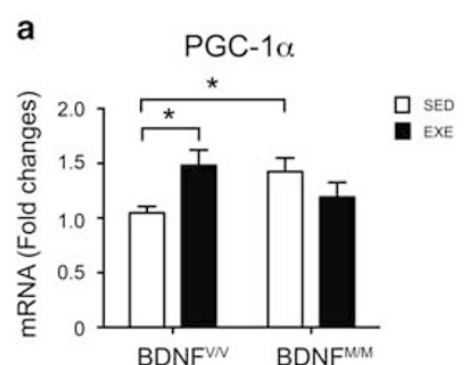

C

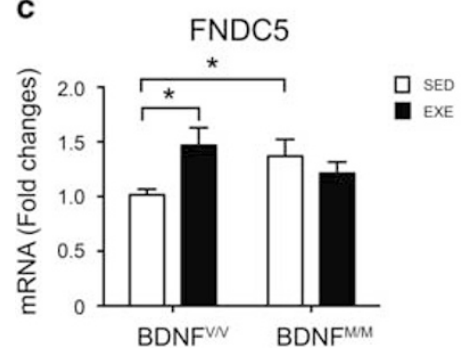

b

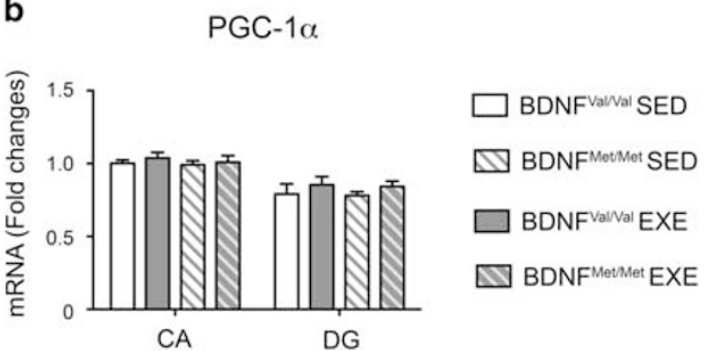

d

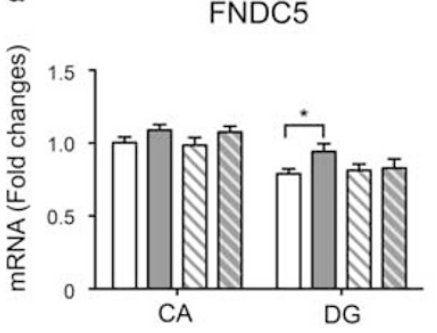

Figure 5 Effect of physical exercise on PGC- $\mid \alpha$ and FNDC5 gene expression in BDNF ${ }^{\mathrm{Val} / \mathrm{Val}}$ and BDNFMet/Met mice. (a, c) Physical exercise significantly increases the mRNA levels of PGC- $\mid \alpha$ and FNDC5 only in the gastrocnemius muscle of BDNFVal/Val mice $(n=9-13$ mice per group). (b) There are no significant differences in the PGC- I $\alpha$ mRNA levels among all different groups. (d) Physical exercise significantly increases mRNA levels of FNDC5 in the DG only in BDNF ValNal mice $(n=6-7$ mice per group). Data are expressed as means \pm SEM. Two-way ANOVA followed by Fischer's LSD post hoc analysis. *P $<0.05$. CA, cornus ammonis; DG, dentate gyrus; EXE, exercise; SED, sedentary.

gene expression were not due to different extent of exercise, as the daily average distance run by $\mathrm{BDNF}^{\mathrm{Val} / \mathrm{Val}}$ wild-type and BDNF ${ }^{\text {Met/Met }}$ mutant mice was similar.

While substantial evidence indicate that exercise affects the hippocampal function by increasing BDNF levels, few reports have thoroughly investigated the involvement of the BDNF pathway in the outcome of exercise (Duman et al, 2008; Li et al, 2008). Here, we reported that exercise fails to induce anxiolytic- and antidepressant-like effects in the Val66Met human polymorphism knock-in mutant mice. These results are consistent with previously published data showing that exercise was not effective in decreasing FST immobility in the heterozygous knock-out BDNF mice (Duman et al, 2008). Moreover, results from the present study complement and extend previous data showing that anxiolytic- and antidepressant-like effects of chronic fluoxetine and acute ketamine treatments, respectively, were absent in $\mathrm{BDNF}^{\mathrm{Met} / \mathrm{Met}}$ mutant mice (Chen et al, 2006; Liu et al, 2012), suggesting a more general ineffectiveness of proadaptive anxiolytic and antidepressant treatments in $\mathrm{BDNF}^{\mathrm{Met} / \mathrm{Met}}$ mice. The therapeutic implication of the failure of $\mathrm{BDNF}^{\mathrm{Met} / \mathrm{Met}}$ mutant mice to show the behavioral changes induced by exercise is significant. Exercise is an affordable treatment that produces extensive favorable effects, both in the central nervous system and in the whole body. However, the behavioral benefits vary in different subjects, suggesting that different factors may interact to produce distinct consequences. Indeed, some studies have addressed whether the BDNF Val66Met polymorphism moderates the response to exercise in human, producing mixed and inconclusive results, probably depending on the ethnic group, gender, age, and type and frequency of the exercise considered (Brown et al, 2014; Gujral et al, 2014; Hopkins et al, 2012; Lemos et al, 2016; Mata et al, 2010; Nascimento et al, 2015).
Although further studies will be necessary to fully elucidate the role of BDNF Val66Met polymorphism in exerciseinduced changes in humans, our results indicate that the presence of BDNF Val66Met polymorphism in homozygosis impairs the anxiolytic and antidepressant beneficial effects of exercise in adult male mice.

The present results showing that exercise failed to promote behavioral changes and to increase hippocampal BDNF levels in the $\mathrm{BDNF}^{\mathrm{Met} / \mathrm{Met}}$ mice are in line with the neurotrophic hypothesis of depression that postulates a central role of the BDNF pathway in the therapeutic efficacy of antidepressant treatments. Indeed, almost all the pharmacological and environmental antidepressant treatments used to date increase BDNF expression, and the genetic ablation of BDNF in animal models prevents the response to antidepressant treatments (Lindholm and Castren, 2014; Monteggia et al, 2004; Monteggia et al, 2007; Musazzi et al, 2009). Our observations are also in line with recent studies showing that exercise increases peripheral levels of BDNF only in wild type, but not in humans carrying the Val66Met SNP (Lemos et al, 2016; Nascimento et al, 2015), suggesting an additional possible common feature between mice and humans carrying the Val66Met SNP.

Interestingly, we found that $\operatorname{TrkB}$ protein levels were overall augmented in the BDNF ${ }^{\text {Met/Met }}$ hippocampus of sedentary mice. Increased levels of TrkB have been previously reported also in the hippocampus of heterozygous $\mathrm{BDNF}^{+/-}$and may be due to a compensatory effect aimed at preventing hippocampal dysfunction (Carreton et al, 2012). Moreover, it has been shown that prolonged BDNF exposure downregulates the expression of TrkB levels (Chen et al, 2005; Sommerfeld et al, 2000); therefore, the upregulation of TrkB in $\mathrm{BDNF}^{\mathrm{Met} / \mathrm{Met}}$ mice may be a direct consequence of diminished BDNF protein levels. However, further studies 
will be necessary to elucidate whether the TrkB protein differences observed in the whole hippocampus are equally distributed among the different sub-regions or whether they are more pronounced in the DG respect to the CA regions.

\section{A Role for FNDC5 in the Lack of Physical Exercise-Induced Stimulation of BDNF Expression in BDNF $^{\text {Met/Met }}$ Mutant Mice}

Recently, it has been reported that exercise increases FNDC5 levels in both the quadriceps muscle and hippocampus. Interestingly, overexpression of FNDC5 in the periphery, by adenoviral vector infection, has been shown to be sufficient to induce upregulation of BDNF in the hippocampus, suggesting that the signal carried by a secreted circulating form of FNDC5 is able to cross the blood-brain barrier and induces hippocampal gene expression changes (Wrann et al, 2013). In line with these results, we found upregulation of FNDC5 only in the $\mathrm{BDNF}^{\mathrm{Val} / \mathrm{Val}}$ gastrocnemius and DG after 4 weeks of exercise. Remarkably, in $\mathrm{BDNF}^{\text {Met/Met }}$ mice exercise failed to enhance the FNDC5 mRNA levels in the gastrocnemius and DG, and this was paralleled by a reduced increase of BDNF levels in the DG after exercise. Further studies will be necessary to reveal the specific contribution of local $v s$ systemic FNDC5 to exercise-induced hippocampal BDNF expression, by using selective deletion of FNDC5 in different tissues. However, the present results suggest that the compromised upregulation of hippocampal BDNF levels is linked to the failed increase of FNDC5 in $\mathrm{BDNF}^{\mathrm{Met} / \mathrm{Met}}$ mice.

\section{A Role for Neurogenesis and BDNF Expression in the Beneficial Effect of Physical Exercise}

Hippocampal neurogenesis has been proposed as a major mechanism in the therapeutic efficacy of chronic antidepressants (Santarelli et al, 2003). However, some recent studies have suggested both neurogenesis-dependent and -independent mechanisms underlying the anxiolytic and antidepressant action, as some studies showed that increased neurogenesis induced by specific treatments is not critical for behavioral changes (Hill et al, 2015; Jedynak et al, 2014; Meshi et al, 2006; Sahay et al, 2011). Here, we reported that exercise significantly increased the total number of newborn neurons in both $\mathrm{BDNF}^{\mathrm{Val} / \mathrm{Val}}$ and $\mathrm{BDNF}^{\mathrm{Met} / \mathrm{Met}}$ mice, and that $\mathrm{BDNF}^{\mathrm{Met} / \mathrm{Met}}$ mice had overall fewer BrdU-positive cells. Our data could suggest that exercise-induced increases of neurogenesis may not be critical for the behavioral changes of exercise in $\mathrm{BDNF}^{\mathrm{Met} / \mathrm{Met}}$ mice, which is consistent with the neurogenesis-independent mechanism hypothesis reported in some behavioral paradigms.

Interestingly, similar data were also reported after chronic fluoxetine treatments in $\mathrm{BDNF}^{\text {Met/Met }}$ mice, in which there was an increase in newborn neuronal survival after antidepressant administration without behavioral benefit (Bath et al, 2012; Chen et al, 2006).

We observed that the exercise-increased total BDNF mRNA expression in the $\mathrm{BDNF}^{\mathrm{Val} / \mathrm{Val}}$ hippocampus was mainly due to the upregulation of BDNF in the DG. This increase was attributable to the augmented levels of BDNF transcripts 1-2-4-6. Interestingly, we found that in sedentary mice BDNF- 6 was reduced in the DG of BDNF${ }^{\mathrm{Met} / \mathrm{Met}}$ mice, confirming our previous data showing an overall reduction of BDNF-6 in the BDNF ${ }^{\text {Met/Met }}$ compared with BDNF $\mathrm{Bal}^{\mathrm{Val} / \mathrm{Val}}$ hippocampus (Mallei et al, 2015). Remarkably, the upregulation of total and specific BDNF transcripts induced by exercise was absent or reduced in $\mathrm{BDNF}^{\text {Met/Met }}$ mice. These results suggest that modulation of BDNF in the DG has an important role in the behavioral effect produced by exercise. Previous evidence showing that specific ablation of BDNF in the DG, but not in the hippocampal CA1 region, attenuates antidepressant efficacy is consistent with this hypothesis (Adachi et al, 2008).

In summary, our results demonstrate that $\mathrm{BDNF}^{\mathrm{Met} / \mathrm{Met}}$ mice do not benefit from the anxious- and antidepressant-like effects of chronic exercise and show a likely mechanism underlying this impaired response. These results highlight the importance of genetic factors in moderating the response to exercise, and how much genetic variations should be taken into consideration in clinical trials. Moreover, our study highlights the importance of using animal models unresponsive to pharmacological and environmental treatments, like the knock-in mouse for the human BDNF Val66Met polymorphism, to provide further evidence on the mechanisms underlying the beneficial effects of exercise. A better understanding of the relationship between the genetic profile and changes in response to exercise will allow developing more personalized environmental and pharmacological treatments.

\section{FUNDING AND DISCLOSURE}

The authors declare no conflict of interest.

\section{ACKNOWLEDGMENTS}

We thank Tania Galdini for technical help. This research was supported by MIUR (PRIN 2010 prot. 2010N8PBAA_004) to $\mathrm{MP}$ and NIH (NS052819) to FSL.

\section{REFERENCES}

Adachi M, Barrot M, Autry AE, Theobald D, Monteggia LM (2008). Selective loss of brain-derived neurotrophic factor in the dentate gyrus attenuates antidepressant efficacy. Biol Psychiatry 63: 642-649.

Aid T, Kazantseva A, Piirsoo M, Palm K, Timmusk T (2007). Mouse and rat BDNF gene structure and expression revisited. $J$ Neurosci Res 85: 525-535.

Baj G, D'Alessandro V, Musazzi L, Mallei A, Sartori CR, Sciancalepore $M$ et al (2012). Physical exercise and antidepressants enhance BDNF targeting in hippocampal CA3 dendrites: further evidence of a spatial code for BDNF splice variants. Neuropsychopharmacology 37: 1600-1611.

Baj G, Del Turco D, Schlaudraff J, Torelli L, Deller T, Tongiorgi E (2013). Regulation of the spatial code for BDNF mRNA isoforms in the rat hippocampus following pilocarpine-treatment: a systematic analysis using laser microdissection and quantitative real-time PCR. Hippocampus 23: 413-423.

Bath KG, Jing DQ, Dincheva I, Neeb CC, Pattwell SS, Chao MV et al (2012). BDNF Val66Met impairs fluoxetine-induced enhancement of adult hippocampus plasticity. Neuropsychopharmacology 37: 1297-1304.

Bostrom P, Wu J, Jedrychowski MP, Korde A, Ye L, Lo JC et al (2012). A PGC1-alpha-dependent myokine that drives brown-fatlike development of white fat and thermogenesis. Nature 481: 463-468. 
Brown BM, Bourgeat P, Peiffer JJ, Burnham S, Laws SM, Rainey-Smith SR et al (2014). Influence of BDNF Val66Met on the relationship between physical activity and brain volume. Neurology 83: 1345-1352.

Carreton O, Giralt A, Torres-Peraza JF, Brito V, Lucas JJ, Gines S et al (2012). Age-dependent decline of motor neocortex but not hippocampal performance in heterozygous BDNF mice correlates with a decrease of cortical PSD-95 but an increase of hippocampal TrkB levels. Exp Neurol 237: 335-345.

Chen ZY, Ieraci A, Tanowitz M, Lee FS (2005). A novel endocytic recycling signal distinguishes biological responses of Trk neurotrophin receptors. Mol Biol Cell 16: 5761-5772.

Chen ZY, Jing D, Bath KG, Ieraci A, Khan T, Siao CJ et al (2006). Genetic variant BDNF (Val66Met) polymorphism alters anxietyrelated behavior. Science 314: 140-143.

Christie BR, Eadie BD, Kannangara TS, Robillard JM, Shin J, Titterness AK (2008). Exercising our brains: how physical activity impacts synaptic plasticity in the dentate gyrus. Neuromolecular Med 10: 47-58.

Deslandes A, Moraes H, Ferreira C, Veiga H, Silveira H, Mouta R et al (2009). Exercise and mental health: many reasons to move. Neuropsychobiology 59: 191-198.

Duman CH, Schlesinger L, Russell DS, Duman RS (2008). Voluntary exercise produces antidepressant and anxiolytic behavioral effects in mice. Brain Res 1199: 148-158.

Egan MF, Kojima M, Callicott JH, Goldberg TE, Kolachana BS, Bertolino A et al (2003). The BDNF val66met polymorphism affects activity-dependent secretion of BDNF and human memory and hippocampal function. Cell 112: 257-269.

Farmer J, Zhao X, van Praag H, Wodtke K, Gage FH, Christie BR (2004). Effects of voluntary exercise on synaptic plasticity and gene expression in the dentate gyrus of adult male SpragueDawley rats in vivo. Neuroscience 124: 71-79.

Gujral S, Manuck SB, Ferrell RE, Flory JD, Erickson KI (2014). The BDNF Val66Met polymorphism does not moderate the effect of self-reported physical activity on depressive symptoms in midlife. Psychiatry Res 218: 93-97.

Hagihara H, Toyama K, Yamasaki N, Miyakawa T (2009). Dissection of hippocampal dentate gyrus from adult mouse. $J$ Vis Exp 33: 1543.

Hariri AR, Goldberg TE, Mattay VS, Kolachana BS, Callicott JH, Egan MF et al (2003). Brain-derived neurotrophic factor val66met polymorphism affects human memory-related hippocampal activity and predicts memory performance. J Neurosci 23: 6690-6694.

Hill AS, Sahay A, Hen R (2015). Increasing adult hippocampal neurogenesis is sufficient to reduce anxiety and depression-like behaviors. Neuropsychopharmacology 40: 2368-2378.

Hopkins ME, Davis FC, Vantieghem MR, Whalen PJ, Bucci DJ (2012). Differential effects of acute and regular physical exercise on cognition and affect. Neuroscience 215: 59-68.

Hopkins ME, Nitecki R, Bucci DJ (2011). Physical exercise during adolescence versus adulthood: differential effects on object recognition memory and brain-derived neurotrophic factor levels. Neuroscience 194: 84-94.

Ieraci A, Mallei A, Musazzi L, Popoli M (2015). Physical exercise and acute restraint stress differentially modulate hippocampal brain-derived neurotrophic factor transcripts and epigenetic mechanisms in mice. Hippocampus 25: 1380-1392.

Intlekofer KA, Berchtold NC, Malvaez M, Carlos AJ, McQuown SC, Cunningham MJ et al (2013). Exercise and sodium butyrate transform a subthreshold learning event into long-term memory via a brain-derived neurotrophic factor-dependent mechanism. Neuropsychopharmacology 38: 2027-2034.

Jedynak P, Kos T, Sandi C, Kaczmarek L, Filipkowski RK (2014). Mice with ablated adult brain neurogenesis are not impaired in antidepressant response to chronic fluoxetine. J Psychiatr Res 56: $106-111$.
Lemos JR Jr, Alves CR, de Souza SB, Marsiglia JD, Silva MS, Pereira AC et al (2016). Peripheral vascular reactivity and serum BDNF responses to aerobic training are impaired by the BDNF Val66Met polymorphism. Physiol Genomics 48: 116-123.

Li Y, Luikart BW, Birnbaum S, Chen J, Kwon CH, Kernie SG et al (2008). TrkB regulates hippocampal neurogenesis and governs sensitivity to antidepressive treatment. Neuron 59: 399-412.

Lim YY, Villemagne VL, Laws SM, Ames D, Pietrzak RH, Ellis KA et al (2014). Effect of BDNF Val66Met on memory decline and hippocampal atrophy in prodromal Alzheimer's disease: a preliminary study. PLoS One 9: e86498.

Lindholm JS, Castren E (2014). Mice with altered BDNF signaling as models for mood disorders and antidepressant effects. Front Behav Neurosci 8: 143.

Liu RJ, Lee FS, Li XY, Bambico F, Duman RS, Aghajanian GK (2012). Brain-derived neurotrophic factor Val66 Met allele impairs basal and ketamine-stimulated synaptogenesis in prefrontal cortex. Biol Psychiatry 71: 996-1005.

Liu YF, Chen HI, Yu L, Kuo YM, Wu FS, Chuang JI et al (2008). Upregulation of hippocampal TrkB and synaptotagmin is involved in treadmill exercise-enhanced aversive memory in mice. Neurobiol Learn Mem 90: 81-89.

Lyons MR, West AE (2011). Mechanisms of specificity in neuronal activity-regulated gene transcription. Prog Neurobiol 94: 259-295.

Mallei A, Baj G, Ieraci A, Corna S, Musazzi L, Lee FS et al (2015). Expression and dendritic trafficking of BDNF-6 splice variant are impaired in knock-in mice carrying human BDNF Val66Met polymorphism. Int J Neuropsychopharmacol 18: pii: pyv069.

Mata J, Thompson RJ, Gotlib IH (2010). BDNF genotype moderates the relation between physical activity and depressive symptoms. Health Psychol 29: 130-133.

Mattson MP (2015). Lifelong brain health is a lifelong challenge: from evolutionary principles to empirical evidence. Ageing Res Rev 20: 37-45.

Meshi D, Drew MR, Saxe M, Ansorge MS, David D, Santarelli L et al (2006). Hippocampal neurogenesis is not required for behavioral effects of environmental enrichment. Nat Neurosci 9: 729-731.

Monteggia LM, Barrot M, Powell CM, Berton O, Galanis V, Gemelli T et al (2004). Essential role of brain-derived neurotrophic factor in adult hippocampal function. Proc Natl Acad Sci USA 101: 10827-10832.

Monteggia LM, Luikart B, Barrot M, Theobold D, Malkovska I, Nef S et al (2007). Brain-derived neurotrophic factor conditional knockouts show gender differences in depression-related behaviors. Biol Psychiatry 61: 187-197.

Musazzi L, Cattaneo A, Tardito D, Barbon A, Gennarelli M, Barlati S et al (2009). Early raise of BDNF in hippocampus suggests induction of posttranscriptional mechanisms by antidepressants. BMC Neurosci 10: 48.

Nascimento CM, Pereira JR, Pires de Andrade L, Garuffi M, Ayan C, Kerr DS et al (2015). Physical exercise improves peripheral BDNF levels and cognitive functions in mild cognitive impairment elderly with different bdnf Val66Met genotypes. J Alzheimers Dis 43: 81-91.

Ninan I, Bath KG, Dagar K, Perez-Castro R, Plummer MR, Lee FS et al (2010). The BDNF Val66Met polymorphism impairs NMDA receptor-dependent synaptic plasticity in the hippocampus. J Neurosci 30: 8866-8870.

Notaras M, Hill R, van den Buuse M (2015). The BDNF gene Val66Met polymorphism as a modifier of psychiatric disorder susceptibility: progress and controversy. Mol Psychiatry 20: 916-930.

Phillips C, Baktir MA, Srivatsan M, Salehi A (2014). Neuroprotective effects of physical activity on the brain: a closer look at trophic factor signaling. Front Cell Neurosci 8: 170.

Sahay A, Scobie KN, Hill AS, O'Carroll CM, Kheirbek MA, Burghardt NS et al (2011). Increasing adult hippocampal neurogenesis is sufficient to improve pattern separation. Nature 472: 466-470. 
Santarelli L, Saxe M, Gross C, Surget A, Battaglia F, Dulawa S et al (2003). Requirement of hippocampal neurogenesis for the behavioral effects of antidepressants. Science 301: 805-809.

Schuch FB, Deslandes AC, Stubbs B, Gosmann NP, Silva CT, Fleck MP (2016). Neurobiological effects of exercise on major depressive disorder: A systematic review. Neurosci Biobehav Rev 61: 1-11.

Sommerfeld MT, Schweigreiter R, Barde YA, Hoppe E (2000). Down-regulation of the neurotrophin receptor TrkB following ligand binding. Evidence for an involvement of the proteasome and differential regulation of TrkA and TrkB. J Biol Chem 275: 8982-8990.

Stranahan AM, Khalil D, Gould E (2007). Running induces widespread structural alterations in the hippocampus and entorhinal cortex. Hippocampus 17: 1017-1022.

van Praag H, Christie BR, Sejnowski TJ, Gage FH (1999). Running enhances neurogenesis, learning, and long-term potentiation in mice. Proc Natl Acad Sci USA 96: 13427-13431.
Vaynman S, Ying Z, Gomez-Pinilla F (2004). Hippocampal BDNF mediates the efficacy of exercise on synaptic plasticity and cognition. Eur J Neurosci 20: 2580-2590.

Verhagen M, van der Meij A, van Deurzen PA, Janzing JG, Arias-Vasquez A, Buitelaar JK et al (2010). Meta-analysis of the BDNF Val66Met polymorphism in major depressive disorder: effects of gender and ethnicity. Mol Psychiatry 15: 260-271.

Vivar C, Potter MC, van Praag H (2013). All about running: synaptic plasticity, growth factors and adult hippocampal neurogenesis. Curr Top Behav Neurosci 15: 189-210.

Voss MW, Vivar C, Kramer AF, van Praag H (2013). Bridging animal and human models of exercise-induced brain plasticity. Trends Cogn Sci 17: 525-544.

Wrann CD, White JP, Salogiannnis J, Laznik-Bogoslavski D, $\mathrm{Wu}$ J, Ma D et al (2013). Exercise induces hippocampal BDNF through a PGC-1alpha/FNDC5 pathway. Cell Metab 18: 649-659.

Supplementary Information accompanies the paper on the Neuropsychopharmacology website (http://www.nature.com/npp) 